\title{
Chapter 23 \\ Role of Self-efficacy in the Learning Output of Engineering Education
}

\author{
Abhijith Venugopal (D), Rajni Singh (D), and Devika ${ }^{\mathbb{D}}$
}

\begin{abstract}
Self-efficacy, one's perception and self-belief in their abilities to do a particular task successfully, plays a crucial part in engineering education. It helps students enhance and strengthen their learning skills. The recent research has added multifaceted and integrated self-efficacy as the main factor of learning, both theoretical and practical. When placed in the professional situation, engineering students seem to face challenges to make significant use of their knowledge despite rigorous exposure to and training in core competency, communication skills, multidisciplinary team work, etc. The paper aims to study the concept of self-efficacy and trace its role in shaping the engineering skills of students. The study is descriptive in nature. The findings indicate that self-efficacy has an essential role in reinforcing the learning output of engineering education.
\end{abstract}

Keywords Self-efficacy $\cdot$ Learning output $\cdot$ Engineering education

\subsection{Introduction}

Engineering education seems to address essential life and career skills to deal with financial pressure, career opportunities, time management, workplace etiquette, and other necessary skills. Engineering education equips the students with engineering knowledge, engineering skills, and engineering habits of mind (Costa and Kallick 2013). Engineers "make things that work" or make things "work better" (ABET 2013) using a set of multiple skills like logical thinking, problem solving, communication

\footnotetext{
A. Venugopal $\cdot$ R. Singh $\cdot$ Devika $(\bowtie)$

Department of Humanities and Social Sciences, Birla Institute of Technology and Science,

Pilani-Campus, Pilani 333031, RJ, India

e-mail: devika@pilani.bits-pilani.ac.in
}
A. Venugopal
e-mail: abhijith.venugopal@pilani.bits-pilani.ac.in
R. Singh
e-mail: rajni.singh@pilani.bits-pilani.ac.in

K. S. Sangwan and C. Herrmann (eds.), Enhancing Future Skills and Entrepreneurship, Sustainable Production, Life Cycle Engineering and Management, https://doi.org/10.1007/978-3-030-44248-4_23 
skills, spatial ability, technical skills, tinkering skills, and engineer design skills. Students with high engineering self-efficacy strive to acquire knowledge through task based activities, develop new skills, and apply technical academic knowledge in engineering. Students' beliefs about their capabilities in engineering-related areas influence their career choice (Lent and Brown 2006; Zeldin et al. 2008), academic behaviors and choices, goal orientation, task value, and interest in and usefulness of their tasks (Schunk et al. 2013; Bong 2001). Consequently, the demand for efficient, autonomous and competent future engineers (Holvikivi 2007) is high. These curious, optimistic, resourceful, resilient and reflective lifelong learners need to be fully prepared beyond the academic scope. Thus, ABET (Accreditation Board for Engineering and Technology) proposes training in ethics, lifelong learning, communication, and working in multidisciplinary teams to help them overcome the professional challenges. The knowledge and skills that future engineers must wield for professional execution are one of the crucial areas of research in engineering education along with technical knowledge, interpersonal and social skills.

The role of self-efficacy is widely discussed by the researchers of education and learning like Albert Bandura, Frank Pajares, Dale Schunk, Megan Tschannen-Moran, etc. Self-efficacy is "not the skills one has, but the conviction of what one can accomplish with whatever skills one possesses". It is a set of context specific beliefs about competence to perform given academic tasks at designated levels (Bandura 1997; Schunk 1985). Self-efficacy arises from the gradual acquisition of complex cognitive, social, linguistic, and/or physical skills through experience. Commonly understood as domain-specific (Schwarzer and Hallum 2008), skills-specific, task-specific and context-specific rather than a global judgment of ability, self-efficacy influences the choice, level, amount of effort and perseverance in the task performance (Bandura 1997). Academic self-efficacy affects academic achievement, academic persistence, career choices, mastery goal orientation, task value, etc. Thus, the present study aims to analyze the role of self-efficacy in engineering education by focusing on the learning outcomes of engineering education.

This study is based only on the research papers obtained from online data bases. Other sources like books, research reports and monographs are not included in this study. The study is limited to the premises of engineering skills and other technical aspects are out of the domain of this paper. Revealing the role of self-efficacy in engineering education, this study helps the engineering students/learners to practice accordingly as it influences the performance output.

Objectives of this paper are to trace the sources, influencing factors, types and instruments of self-efficacy; and to study how self-efficacy correlates with the learning output in engineering education.

\subsection{Methodology}

This qualitative study has a descriptive research design. The engineering educationspecific research articles are obtained from secondary sources like Scopus indexed/approved online data bases. Selection criterion used specific key words 
related to the study like 'engineering education', 'self-efficacy', and 'engineering learning output'.

\subsection{Self-efficacy: Levels, Sources, Types and Instruments}

General self-efficacy is a sense of personal competence to deal with stressful situations (Schwarzer and Hallum 2008). Self-efficacy is more of a criterion-referenced evaluation of self-concept, self-belief, self-regulation and motivation (Bandura 1997; Bong and Clark 1999; Zimmerman 2000). It measures performance capabilities, not physical or psychological characteristics. It is a strong predictor of not only interest in engineering (Britner and Pajares 2006; Mau 2003) but also emotional reactions, persistence, etc. (Bandura 1997). Self-efficacy has two components: efficacy expectation (the potential to perform a particular task) and outcome expectancy (successful performance assurance). Self-efficacy has three dimensions: magnitude (level of task difficulty); strength (strong/weak conviction about magnitude); and generality (degree of generalization). The magnitude and strength of self-efficacy can influence choice of settings and activities, skill acquisition, effort expenditure, initiation, etc.

Self-efficacy becomes effective when all these dimensions and sources start influencing concurrently which also determines the level of self-efficacy.

\subsubsection{High and Low Level}

The two levels of self-efficacy, higher and lower, affect the performance output. Individuals with high efficacious beliefs willingly engage in challenging tasks, invest greater effort and persistence, and show superior performance output (Bong 2001; Bandura 1997). They better deal with the challenges, develop resolution strategies, exhibit higher achievement and find their work important, useful and interesting. The failure to utilize their capabilities is an indicator of low self-efficacy.

The level of self-efficacy is also dependent on the effectiveness of its sources, and magnitude, strength and generality of self-efficacy.

\subsubsection{Sources of Self-efficacy}

Mastery experiences mark the knowledge acquired through re-collections, accomplishments, hands-on-work experiences, and judgments on the competence of learner's previous attainments in a related task. Vicarious experiences enhance self-efficacy when engineering students see others with same potential performing the desired skills, solve the problems collectively, assess the skills of their peers, 
and induce a belief in their own skills to perform the same task. Verbal persuasion is encouraging judgments, constructive feedbacks and positive appraisals from teachers/role models, friends, etc. Physiological/emotive arousal is the experience of anxiety, stress, fatigue, etc. Favorable reinforcement helps positively (Bandura 1997; Ponton et al. 2001).

These sources, either individually or in combination, can affect the level of the learner's self-efficacy.

\subsubsection{Types of Self-efficacy}

Self-efficacy, during 1980s and 1990s, was branched into, 'career/occupational selfefficacy, (related to career aspects of self-efficacy construct like interest, career choice, etc.) (Betz and Hackett 1981), 'academic milestones self-efficacy' (a person's ability to cope through barrier situations) (Lent et al. 1986) and 'mathematics and science self-efficacy' (significantly predicts a person's science grade (Britner and Pajares 2006). Another classification of self-efficacy is: self-efficacy for selfregulated learning (self-efficacy that promotes/enhances self-learning), self-efficacy for academic achievement, course-specific self-efficacy, content specific self-efficacy and problem-specific self-efficacy (Bong 2001). Job Related Self-efficacy (selfbeliefs on the capable skills which is related to different professions of engineering) comprises math skills, problem solving skills, technical/computer skills, analytical skills, and creativity. Interpersonal self-efficacy (skills that promotes different personal skills) comprises communication, teamwork, and leadership skills. Life skills self-efficacy (Life skills are those skills which would be useful in everyday life.) comprises of time management, organizational skills, and attention to details (Dent et al. 2018).

Since there are multiple types of self-efficacy, the divisions and measurements of self-efficacy also get framed accordingly.

\subsubsection{Instruments of Engineering Self-efficacy}

Academic Milestones measure was modified as per engineering education by including "engineering major" in the items to help students situate their selfefficacy ratings (Lent et al. 1986). General academic self-efficacy scale measures engineering students' beliefs in their capabilities to perform academically (Dunlap 2005). Self-efficacy for self-regulated learning in and academic achievement measures engineering students' performance (academic and learning) (Yildirim et al. 2010). General Engineering Self-efficacy Scale measures general engineering skills (Mamaril 2016). Engineering design self-efficacy measures specific set of design skills (Carberry et al. 2010). The Engineering Skills Assessment scale measures 11 skill areas that students believe are important for career: communication, team work, 
math and science, creative ability, problem solving skills, leadership and management skills, technical skills and knowledge, time management skills, analytical skills, orderliness and organizational skills, attention to details (Yildirim et al. 2010). Of all the scale mentioned above, it has been found that except Engineering Skills Assessment scale all other do not measure the engineering skills directly which reflects the need for better and more focused scales for measuring engineering skills.

Self-efficacy, with its effect on skill development, academic performance, outcome expectation, etc., contributes to the learning outcomes of engineering education. Importance of self-efficacy in skill development need not be questioned.

\subsection{Learning Output of Engineering Education}

The accrediting agencies, ABET and others, and researchers have stated clearly the learning outcomes of engineering education. The learning outcomes are basically dependent on skills required by engineers at their workplace. The learning outcomes discussed below, based on American Association of Engineering Societies (AAES) (Engineering Competency Model-DRAFT 2015), are divided into four areas in a broader way and further discussed on the basis of other research.

\subsubsection{Personal Effectiveness}

Lifelong learning. Lifelong learning/life-wide learning results from the learner's recognition of the need for and an ability to expand means of knowledge beyond the scope of formal education. An engineering context and dynamic nature of learning skills allow individuals to acquire knowledge in the best possible way (ABET 2013; Darabi 2017; Yellamraju et al. 2017).

Personal skills. It includes self-management, emotions, work-life balance/health, honesty, confidence, initiative, dependability, and reliability. Practical thinking, and binding values and attitudes towards their own ability and those of their peers (Yellamraju et al. 2017; Male et al. 2009; Baker et al. 2008) keep them self-motivated and positive.

Professionalism. Knowing about recent trends of the field, networking, meeting deadlines, adapting to change, willing and persistent to try new processes, they exhibit leadership qualities. Successful conflict resolution and action orientation help engineers take decisions with time and knowledge constrains, avoid delays, and maintain a sense of urgency (ABET 2013; Male et al. 2009; Direito et al. 2012).

Personal effectiveness deals with the interpersonal self-efficacy which promotes interpersonal skills and life skills. Learners can use their self-regulated learning to regulate their personal effectiveness. 


\subsubsection{Industry-Wide Technical}

Foundations of Engineering. Understanding the relation between theory and application (Baker et al. 2008), they use the acquired knowledge to understand the impact of engineering solutions in a global, economic, environmental, and societal context (Male et al. 2009; Carlson 2018; Loveland and Dunn 2014; González-Lizardo 2008).

Design. Design processes support active and self-directed learning; learners imagine and understand how a part works together in the first view itself (ABET 2013; Carberry et al. 2010; Baker et al. 2008; Lucas et al. 2014).

Sustainability and Social and Environmental Impact. Engineering education provides the learning ground to formulate, analyze, advocate health and safety issues, take considered risks. Responsibilities include awareness of life-cycle principles, environmental impact, sustainability, and professional practices (ABET 2013; Male et al. 2009; Carlson 2018).

Professional Ethics. Impact of any new product or design (unexpected and undesirable) on people, systems, and the environment must be carefully sensitised by a prism of myriad possibilities. Ethically conscious, they conduct risk analysis on their research designs - for example, considering disposal of waste from the engineering process. (ABET 2013; Carlson 2018; Loveland and Dunn 2014; Lucas et al. 2014; Grubbs et al. 2018).

Industry wide technical is the combination of occupational/career self-efficacy, academic milestone self-efficacy, interpersonal self-efficacy and job skills selfefficacy. It provides a broad and inclusive understanding in different areas where execution of tasks poses real, different and unpracticed challenges.

\subsubsection{Workplace}

Team Work. It demands managing projects and contracts in diverse discipline and fields using strategic planning, mentoring and interacting with people, showing concern for others, voluntarily sharing information, ensuring fare decisions and facilitating their individual contribution (ABET 2013; Dent et al. 2018; Male et al. 2009; Loveland and Dunn 2014; NAE Annual 2010).

Working with Tools and Technology. The most important learning is to distinguish between unquestioned acceptance for technological change and thoughtful understanding of all aspects of change (ABET 2013; Baker et al. 2008; Loveland and Dunn 2014).

Problem Solving. Problem solving is not same as problem finding. Listening to and recitation of details are essential for sophisticated problem solving (Lucas et al. 2014; Nordstrom and Korpelainen 2011). Open-ended problem solving is an efficacious tool of practical thinking (Loveland and Dunn 2014). Formulating and analysing the model of a problem, doing back-of-the-envelope calculations to show 
workability (Baker et al. 2008), and asserting approaches or needs develop a path to solution (Male et al. 2009).

Creative Thinking. Flexibility, originality, fluency, and associative thinking mark thinking about something in a novel, diverse, quick and different way. Using elaboration, brainstorming, modification, and attribute listing, learners explore, engage, and evaluate to generate, present and sum up convincingly (Baker et al. 2008; Loveland and Dunn 2014).

Different learning outputs under workplace are attributed to multiple aspects such as individual and collective effort making, knowledge of subject, instruments, and challenging situations. Workplace learning outputs directly contribute to the jobrelated self-efficacy.

\subsubsection{Academic}

Communication. Communication skills (oral and written) comprise background explanation and meaningful flow of ideas (Yellamraju et al. 2017; Grubbs et al. 2018). Communication, a process in which people try to inform and educate is an essentiality of engineering habits of mind. Professionals need to remain up-to-date (Male et al. 2009).

Mathematics. There is a need of Mathematics self-efficacy to handle mathematical rigor, remember details of definition, understand and apply mathematical concepts to problems. Deductive reasoning skills are used to select an appropriate computation and estimation method to carry out the mathematical processes accurately (Britner and Pajares 2006; Yellamraju et al. 2017; Baker et al. 2008).

Sciences. As a bridge between conceptual and practical learning, basic sciences contribute to creative/practical/utilitarian engineering practices. Systematic content knowledge (multiple angles, breadth and depth of knowledge) is used to overcome multiple realistic challenges (ABET 2013; Zeldin et al. 2008; Loveland and Dunn 2014; Lucas et al. 2014).

Critical and Analytical Thinking. Engineering students use cause-effect, patterning, analogies, forecasting, critiquing, etc. to detect the symptoms of doubtful solutions, assertions and arguments at work (Yellamraju et al. 2017; Loveland and Dunn 2014). The practical experiments make them handle different domain specific situations as practicing professionals (Baker et al. 2008; Loveland and Dunn 2014).

In academic, knowledge of mathematics and sciences prepares the foundation of engineering education. Engineering education foundation is also supported by communication skills and critical thinking.

All the four areas of learning output are directly related to different sources and types of self-efficacy. The analysis of self-efficacy and learning outcomes of engineering education highlights the relationship between self-efficacy and learning outcomes. The different types of self-efficacy have different roles to play in different skills developed during engineering education. 


\subsection{Conclusions}

Self-efficacy significantly affects the learning output of engineering education. During the process of learning, learners, using self-efficacy construct their own knowledge of disciplinary field, evolve and/or modify the existing knowledge contextually. The conviction of the learners, the active agents of learning, about what they can accomplish with their skills enables them to gain experience using flexible, relative and additive understanding of their knowledge. Conducive learning environment can be used as an asset by the learners who wish to explore new avenues of learning/knowledge. Integrating the previously gained experiences with the recently acquired knowledge, the learner can better understand the differences and nuances of learning. Reflective thinking can contribute to self-regulated learning from contextualising and decontextualising the situations.

\section{References}

ABET (2013) Criteria for accrediting engineering programs. http://www.abet.org/wp-content/upl oads/2015/04/eac-criteria-2013-2014.pdf

Baker D, Krause S, Purzer SY (2008) AC 2008-633: developing an instrument to measure tinkering and technical self-efficacy in engineering. ASEE

Bandura A (1997) Self-efficacy: the exercise of control. Freeman, New York

Betz NE, Hackett G (1981) The relationship of career-related self-efficacy expectations to perceived career options in college women and men. J Counsel Psychol 28:399-410

Bong M (2001) Role of self-efficacy and task-value in predicting college students' course performance and future enrollment intentions. Contemp Educ Psychol 26:553-570. https://doi.org/10. 1006/ceps.2000.1048

Bong M, Clark RE (1999) Comparison between self-concept and self-efficacy in academic motivation research. Educ Psychol 34:139-154. https://doi.org/10.1207/s15326985ep3403_1

Britner SL, Pajares F (2006) Sources of science self-efficacy beliefs of middle school students. JRST 43:485-499

Carberry AR, Lee HS, Ohland MW (2010) Measuring engineering design self-efficacy. J Eng Educ 99:71-80

Carlson WB (2018) Knowledge, skill, and wisdom: reflections on integrating the social sciences and engineering. In: Subrahmanian E, Odumosu T, Tsao JY (eds) Engineering; A better future interplay between engineering, social sciences, and innovation. Springer, United States, pp 187196

Costa A, Kallick B (2013) Dispositions: reframing teaching and learning. Professor John Perkins' review of engineering skills, London

Darabi $\mathrm{H}$ et al (2017) Life after university for engineering graduates. In: 2017 ASEE annual conference and exposition, ASEE

Dent L, Maloney P, Karp T (2018) Self-efficacy development among students enrolled in an engineering service-learning section. IJSLE, Human Eng Soc Entrepre 13:25-44. https://doi.org/10. 24908/ijsle.v13i2.11483

Direito I, Pereira A, Duarte A (2012) Engineering undergraduates' perceptions of soft skills: relations with self-efficacy and learning styles. Soc Behav Sci 55. https://doi.org/10.1016/j.sbspro. 2012.09.571

Dunlap JC (2005) ETR\&D 53:65. https://doi.org/10.1007/BF02504858 
Engineering Competency Model—DRAFT (2015) January. http://www.aaes.org/sites/default/files/ Engineering_Competency_Model_draft-0115.pdf

González-Lizardo AE (2008) Interdisciplinary research for engineering skills development. Acta Universitaria Direccion De Invesyigacion Y Postgrado 18(3), University of Guanajuato

Grubbs EM, Strimel GJ, Huffman T (2018) Engineering education: a clear content base for standards. TET 33-38, ITEEA

Holvikivi J (2007) Learning styles in engineering education: the quest to improve didactic practices. Europ J Eng Educ 32(4):401-408. https://doi.org/10.1080/03043790701332909

Lent RW, Brown SD (2006) On conceptualizing and assessing social cognitive constructs in career research: a measurement guide. J Career Assess 14:12-35. https://doi.org/10.1177/106907270 5281364

Lent RW, Brown SD, Larkin KC (1986) Self-efficacy in the prediction of academic performance and perceived career options. J Counsel Psychol 33:265-269

Loveland T, Dunn D (2014) Teaching engineering habits of mind in technology education. TET 73(8): 13-19

Lucas B, Hanson J, Claxton G (2014) Thinking like an engineer: implications for the education system. RAE, London

Male SA, Bush MB, Chapman ES (2009) Identification of competencies required by engineers graduating in Australia. In: Kestell C, Grainger S, Cheung J (eds) 20th conference of the AAEE: engineering the curriculum. University of Adelaide, pp 882-887

Mamaril A et al (2016) Measuring undergraduate students' engineering self-efficacy: a validation study. J Eng Educ. https://doi.org/10.1002/jee.2012

Mau WC (2003) Factors that influence persistence in science and engineering career aspirations. Career Develop Quart 51(3):234-243. https://doi.org/10.1002/j.2161-0045.2003.tb00604.x

NAE Annual Report (2010). https://www.nae.edu/51959/NAE-Annual-Report-2010

Nordstrom K, Korpelainen P (2011) Creativity and inspiration for problem solving in engineering education. Teach Higher Educ 16(4):439-450. https://doi.org/10.1080/13562517.2011.560379

Ponton M, Horine EJ, Ukeiley LM, Seiner J (2001) Understanding the role of self-efficacy in engineering education. J Eng Educ. https://doi.org/10.1002/j.2168-9830.2001.tb00599.x

Schunk DH (1985) Self-efficacy and classroom learning. Psychol Sch 22:208-223. https://doi.org/ 10.1002/1520-6807(198504)22:2\%3c208:AID-PITS2310220215\%3e3.0.CO;2-7

Schunk DH, Meece JR, Pintrich PR (2013) Motivation in education: theory, research, and applications, 4th edn. Pearson, United States

Schwarzer R, Hallum S (2008) Perceived teacher self-efficacy as a predictor of job stress and burnout: mediation analyses. Appl Psychol 57:152-171. https://doi.org/10.1111/j.1464-0597. 2008.00359.x

Yellamraju T, Magana AJ, Boutin M (2017) Investigating engineering students habits of mind: a case study approach. In: 2017 ASEE ACE, ASEE

Yildirim T, Sacre MB, Shuman L (2010) AC 2010-627: scale development for engineering modeling self-efficacy. ASEE

Zeldin AL, Britner SL, Pajares P (2008) A comparative study of the self-efficacy beliefs of successful men and women in mathematics, science, and technology careers. JRST 45(9):1036-1058. https:// doi.org/10.1002/tea.20195

Zimmerman BJ (2000) Self-efficacy: an essential motive to learn. Contemp Educ Psychol 25:82-91. https://doi.org/10.1006/ceps.1999.1016 
Open Access This chapter is licensed under the terms of the Creative Commons Attribution 4.0 International License (http://creativecommons.org/licenses/by/4.0/), which permits use, sharing, adaptation, distribution and reproduction in any medium or format, as long as you give appropriate credit to the original author(s) and the source, provide a link to the Creative Commons license and indicate if changes were made.

The images or other third party material in this chapter are included in the chapter's Creative Commons license, unless indicated otherwise in a credit line to the material. If material is not included in the chapter's Creative Commons license and your intended use is not permitted by statutory regulation or exceeds the permitted use, you will need to obtain permission directly from the copyright holder.

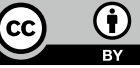

